OPEN ACCESS

Edited by:

Wei Hao,

Central South University, China

Reviewed by:

Marco Di Nicola,

Catholic University of the Sacred

Heart, Italy

Angela Kay Stevens,

Brown University, United States

*Correspondence:

Enrique Moraleda-Barreno enrique.moraleda@dpsi.uhu.es

Specialty section:

This article was submitted to

Addictive Disorders,

a section of the journal

Frontiers in Psychiatry

Received: 25 June 2020

Accepted: 19 August 2020 Published: 08 September 2020

Citation:

Gómez-Bujedo J, Lozano ÓM, Pérez-Moreno PJ, Lorca-Marín JA, Fernández-Calderón F,

Diaz-Batanero $C$ and

Moraleda-Barreno E (2020) Personality Traits and Impulsivity

Tasks Among Substance Use

Disorder Patients: Their Relations and Links With Retention in Treatment.

Front. Psychiatry 11:566240. doi: 10.3389/fpsyt.2020.566240

\section{Personality Traits and Impulsivity Tasks Among Substance Use Disorder Patients: Their Relations and Links With Retention in Treatment}

Jesús Gómez-Bujedo, Óscar M. Lozano, Pedro Juan Pérez-Moreno, José Andrés Lorca-Marín, Fermín Fernández-Calderón, Carmen Diaz-Batanero and Enrique Moraleda-Barreno*

Department of Clinical and Experimental Psychology, University of Huelva, Huelva, Spain

Background: Various authors have described the elements of impulsive approach and inhibitory control in drug users. These two components have been studied in terms of personality traits, performance on tasks that measure impulsive behavior, and neurophysiology. However, few studies have analyzed the association between these constructs. Thus, the aim of the present study is to analyze the associations between personality traits and performance on impulsivity tasks.

Methods: A follow-up study was conducted with a baseline assessment at the beginning and end of treatment. The sample was composed of 121 patients undergoing treatment in therapeutic communities. Personality domains were evaluated through the PID-5. The impulsivity tasks employed were the lowa Gambling Task (IGT), Delay Discounting Test (DDT), Go/No-Go and Stroop test.

Results: A correlation was found between DDT scores and the domains of detachment $(r=-.315 ; p<.01)$, antagonism ( $r=-.294 ; p<.01)$, and disinhibition $(r=.215 ; p<.05)$. Performance on the Stroop task was significantly associated with psychoticism ( $r=.232$; $p<.05)$ and negative affect $(r=.212 ; p<.05)$. Multivariate analysis revealed that IGT scores and negative affect predict retention in treatment.

Conclusions: These findings partially support the hypothesized association between sensation-seeking personality traits and detachment with impulsive choice tasks; and the relationships between negative affect and psychoticism traits with performance on inhibitory control tasks. Further, impulsive choice task scores and negative affect are both shown to predict retention in treatment.

\footnotetext{
Keywords: cognitive impulsivity, Diagnostic and Statistical Manual of Mental Disorders (Fifth Edition), personality traits, Personality Inventory for Diagnostic and Statistical Manual of Mental Disorders (Fifth Edition), substance use disorders, treatment adherence
} 


\section{INTRODUCTION}

The association between personality traits and drug use is a widely studied topic. Until the advent of the DSM-III, substance use disorders were considered to be a subcategory of personality disorders (1). Today, the evidence is inconsistent regarding the existence of an "addictive personality" (2), although some findings suggest an association between certain personality domains and drug use. For example, low conscientiousness has been associated with the initiation of drug use in young people $(3,4)$, while high disinhibition, low conscientiousness, and aggressiveness have been associated with substance use disorder (5). In general terms, there is a consensus that the most impulsive personality traits, and emotional instability, are linked with the appearance of drug-using behaviors. Moreover, substance addiction is often associated with specific impaired Response Inhibition and Salience Attribution (iRISA) networks in addition to comorbidity with other disorders $(6,7)$.

Impulsivity is a complex and multifaceted trait, which has been traditionally evaluated through a multi-method approach that distinguishes between self-report and behavioral tasks. Selfreports are based on questionnaires that ask people about their behavior patterns in certain contexts and are generally the most frequently used methods for studying impulsive personality traits (8). In behavioral tasks, certain performance indicators are used to infer impulsive behavior (e.g., reaction times, alternative choice tasks). These, in turn, can be categorized into impulsive action (response inhibition, inhibitory control), characterized by the inability to stop a prepotent response that the subject might naturally emit, and impulsive choice (impulsive decision making), which is related to the difficulties in optimizing the decision-making process. Further, impulsive action can be differentiated into motor inhibition (related to the ability to inhibit an automated response), and interference control (a cognitive form of inhibition, which involves the suppression of competitive and distracting information to maintain response performance). Broadly speaking, impulsive choice can be evaluated by the delay discounting task, which measures the change in the subjective value of a reward according to the time it takes to be released, and impulsive decision making, which measures decision making under conditions of ambiguity $(9,10)$.

At the trait level, the associations between personality domains, facets of impulsivity, and drug use have been well documented $(11,12)$. Evidence has also been reported in favor of an association between performance on impulsivity tasks and drug use (13-16). However, the associations between performance on neuropsychological impulsivity tasks and the five-factor model personality traits have been less widely studied. In community samples, scores on impulsive choice tasks such as the Iowa Gambling Task (IGT) have been found to be associated with the domains of extraversion, neuroticism, and openness (17-20). Buelow and Cayton (21) also reported a correlation between IGT scores and agreeableness, while other authors have found no association between performance on this behavioral task and any personality trait $(22,23)$. In delay discounting tasks (DDT), poor performance has been associated with low levels of openness and conscientiousness, and high extraversion and neuroticism (24-26). Studies of impulsivity suggest that extraversion influences execution time on the Stroop task, with a positive correlation between the two constructs (27-29), while no association has been found with neuroticism, agreeableness, and conscientiousness. Similarly, other authors have found no association between Stroop scores and personality domains (30). In studies conducted with drug users and healthy volunteers, Ersche et al. (31) found a correlation between performance on executive function tasks and certain facets linked to emotional functioning, impulsive-compulsive, and self-evaluation traits. In subjects with alcohol dependence, Tomassini et al. (32) found that IGT scores were associated with the novelty-seeking and persistence domains of Cloninger's model of personality.

For some authors, the relationships between impulsive personality traits and the execution of impulsivity tasks (in addition to neurophysiological processes) must be related to each other, given that the two processes underlie addiction (33). In particular, in addiction there is a process associated with the propensity or urge to approach drugs; while it is also possible to identify a process associated with a reduced capacity to inhibit this approach behavior. According to this model, the impulsive approach component includes personality domains such as sensitivity to reward, sensation-seeking or extraversion, together with scores on impulsive choice and delay discounting tasks. The inhibitory control component includes personality traits such as constraint and scores on behavioral tasks related to impulsive action or motor disinhibition (33). However, Gullo and Potenza (34) have indicated the need to analyze data from multiple impulsivity measures simultaneously in order to better understand these processes.

In addition, Section III of the Diagnostic and Statistical Manual of Mental Disorders (Fifth Edition) proposes an alternative diagnostic model for personality disorders based on the identification of pathological personality facets. This model allows both the diagnosis of personality disorders and the establishment of clinical profiles in addition to being equivalent to other personality models such as the five-factor model (FFM) (35). Further, previous studies have demonstrated an association between AMPD and the UPPS-P model of impulsivity (36) and its usefulness in identifying the profiles of drug-using patients (37). Therefore, within the field of addiction, this is a useful personality model, from both a clinical and research standpoint.

Thus, the present study had the following objectives:

i. To analyze the correlation between personality traits according to AMPD and scores on impulsivity tasks in a sample of patients with substance dependence. Following the proposal of Gullo et al. (33), we expected to find an association between performance on impulsive choice tasks and those personality traits that are most strongly linked to disinhibition, extraversion, and sensation-seeking, while performance on motor impulsivity tasks will be more strongly associated with negative-affect-related personality traits.

ii. To analyze the predictive capacity of personality traits and performance on impulsivity tasks with regard to treatment 
retention. According to previous studies, patients that show traits and behaviors more strongly linked to sensationseeking are less likely to remain in treatment.

\section{METHOD}

\section{Participants}

The sample was composed of 121 inpatients (91.7\% males) with a mean age of $37.94(\mathrm{SD}=10.23)$ years. The patients were being treated in three public therapeutic communities (TC) located in Andalusia (Spain). These patients were referred from outpatient addiction treatment centers (ATCs). The primary reasons for referral are: i) the inability to maintain abstinence during outpatient treatment; and, ii) the need for intensive and continuous treatment. In all three TCs, patients receive cognitive behavioral treatment for addictions, which is standardized according to a single protocol. This treatment program is multidisciplinary and includes medical and psychological care, as well as health care and participation in educational programs.

A total of $72.7 \%$ of the participants had been diagnosed with cocaine use disorder (CUD) according to DSM-IV criteria, $49.6 \%$ with alcohol use disorder, $37.2 \%$ with cannabis use disorder and $27.3 \%$ with heroin use disorder. Of the sample, $58.3 \%$ had been diagnosed with more than one substance use disorder. During the month prior to admission to the TC, $42.1 \%$ reported using cocaine, $35.5 \%$ alcohol, $33.1 \%$ cannabis, and $16.5 \%$ heroin.

To participate in the study, patients had to meet the following inclusion criteria: 1) No vision problems or other physical impairments that would hinder the completion of computerized tests; 2) the ability to read and write; 3 ) the absence of comorbid mental disorders; 4) be of legal age; and, 5) sign the informed consent form.

With regard to education levels, $63.7 \%$ had completed primary education, $35.5 \%$ secondary education, and $15.7 \%$ had completed university studies. Most of the participants (59.5\%) were unemployed at the time of entering the therapeutic community, $22.3 \%$ were working, and the remaining percentage were retired. In terms of marital status, $10.7 \%$ were married, $65.3 \%$ were single, and the remainder were divorced.

After 1 year of assessment, a total of 38 patients withdrew from their therapeutic process while 83 patients successfully completed the therapeutic objectives of the TC. The former spent a mean of $87.97(\mathrm{SD}=57.29)$ days in treatment and the latter a mean of $202.77(\mathrm{SD}=75.82)$ days, these differences being statistically significant $\left(\mathrm{t}_{93,353}=9.177 ; \mathrm{p}<.01\right)$.

\section{Instruments}

We used the following impulsive decision-making tasks, which are measures related to the impulsive approach component:

- Delay Discounting (38). This questionnaire is composed of a fixed set of 27 options and consists of monetary choice in which participants are asked about their individual preferences when choosing between small but immediate rewards and greater but delayed rewards. In this study we used, as an index of impulsivity, the area under the curve [AUC; (39)]. A higher score on this index is taken to indicate lower impulsivity.

- Iowa Gambling Task (40). This is a classic task for evaluating decision-making under conditions of ambiguity. Participants must choose between four decks of different cards, which have different reinforcement and punishment schedules. The task is to choose cards in order to gain the maximum or greatest benefits, although in the long run these produce losses. The computerized version was employed (41), using the total score as the index of impulsive decision-making. A higher score is associated with more adaptive decision-making.

In order to evaluate inhibitory control, we employed the following tasks:

- Inhibition-Affective Go/No-Go (42). In this task, participants were required to press a key when a Go stimulus (one letter) appeared on the screen ( $80 \%$ of the trials), and to not press the key when the No-Go stimulus appeared on the screen (a different letter; $20 \%$ of the trials). Participants received feedback on their successes and errors through audio signals. The task consisted of two blocks of 60 trials. The first block was administered after neutral images had been displayed, while the second block was administered after viewing positive affective images. All images were extracted from the International Affective Picture System [IAPS; (43)]. The index of impulsivity in this task was the number of commission errors (i.e. responses to No-Go stimuli) in the neutral and positive blocks. A higher number of commission errors is taken to indicate poor inhibitory control.

- Inattention: Stroop Task (44). The Stroop task can also be considered as a measure of response inhibition (45). This task generates interference between the reading of words and the naming of colors (Stroop interference effect), so that the reaction time varies depending on the congruence or incongruence between the word and the color. The participants are required to inhibit the reading of the written word and respond with the color in which it is written. The index of impulsivity in this task is the Stroop Interference score. Increased interference is associated with increased motor impulsivity.

- Substance Dependence Severity Scale (46). The SDSS is a semistructured interview that evaluates the severity of substance dependence. In this study, we assessed the severity of dependence on cocaine, alcohol, cannabis and opiates using the Spanish version adapted to the DSM-5 criteria (47). Reliability, estimated by internal consistency, was higher than. 83 for all substances. A higher score is taken to indicate a higher severity of dependence.

- Personality Inventory for DSM-5 Short Form [PID-5SF; (48)]. We administered the Spanish version of this instrument (49, 50). This instrument originates from the DSM-5 Alternative Model for Personality Disorders [AMPD; (51)] and evaluates the 25 established facets by organizing them into the following five personality domains: negative affect, detachment, antagonism, disinhibition, and psychoticism. These personality domains are 
considered to be the maladaptive extremes of the five-factor model (52). This instrument has shown adequate psychometric properties in terms of reliability and evidence of validity for its use with patients that consume drugs $(50,53)$.

\section{Procedure}

The interviews were conducted by a psychologist with experience in patient assessment, who had been specifically trained to administer these instruments. The interviews were conducted in individual sessions at the centers where the patients were receiving their treatment.

Initially, the therapists informed patients that researchers at the University of Huelva were conducting a study. The therapists specified that their decision to participate (or not) in the study would have no effect on their therapeutic process. If patients agreed to participate, they were then sent to the interviewer.

Prior to administering the tests, the psychologist informed the patients of the objectives of the study and indicated the need to collect data related to their retention/dropout in treatment during the year following the interview. The psychologist also informed patients of their rights during participation and resolved any concerns before the start of the study. Once written informed consent had been given, the administration of the tests began. Initially the psychologist administered the SDSS to the patients. The patients then individually performed the behavioral tasks on a computer. Before starting each test, the interviewer explained the instructions to the patients, and made sure that they had understood them. Before each task, the patients carried out a test. Finally, the psychologist also administered the PID-5 to the patients. The tests lasted approximately 45-60 $\mathrm{min}$.

This study has been approved by the ethics committee of the University of Huelva.

\section{Analysis}

The scores were initially checked for normality using the Shapiro-Wilks test, which confirmed that none of the measures of impulsive behavior followed a normal distribution $\left(\mathrm{W}_{\mathrm{DDT}}=\right.$ $0.93, \mathrm{z}=4.160, \mathrm{p}=.000 ; \mathrm{W}_{\text {IGT }}=0.95, \mathrm{z}=3.417, \mathrm{p}=.000$; Stroop $=$ $\left.0.92, \mathrm{z}=4.554, \mathrm{p}=.000 ; \mathrm{W}_{\mathrm{Go} / \mathrm{no}-\mathrm{Go}}=0.99, \mathrm{z}=1.974, \mathrm{p}=.021\right)$. We therefore decided to use non-parametric tests to test the hypotheses (54). The relationships between the quantitative variables were analyzed using Spearman's Rho correlation coefficient. A Mann-Whitney U test was employed to analyze the correlation between each quantitative variable (i.e. each of the personality traits) and the type of discharge from the TC.
To analyze the predictive capacity of the variables with regard to treatment retention, the Kernel-Based Regularized Least Squares [KRLS; (55)] was used, which allows for conducting a regression analysis without relying on assumptions regarding data distribution. For this, KRLS estimator learns the functional form from the data and thereby protects inferences against misspecification bias. The interpretation and inferences made on the basis of these coefficients are similar to those provided by standard regression models. Two KRLS analyses were conducted in this study. The first included time in treatment as a dependent variable, while the second used retention in treatment as a dependent variable (a value of 0 indicates abandonment of treatment; and a value of 1 indicates discharge from treatment). The independent variables of these analyses were the PID domains and the behavioral measures of impulsivity. Age, gender, and severity of alcohol and cocaine dependence were also introduced into the model in order to control for the effects of these variables.

All analyses were conducted using Stata Vers 14.2 software.

\section{RESULTS}

\section{Associations Between PID Domains and Behavioral Measures of Impulsivity}

Table 1 shows the associations between measures of impulsive choice, motor impulsivity and personality domains. It can be observed that DDT scores are negatively correlated with the domains of detachment, antagonism and disinhibition. This indicates that these personality domains are associated with a more impulsive pattern of decision-making. Among the motor impulsivity tasks, Stroop scores show a statistically significant association with the psychoticism and negative affect domains. Specifically, greater interference is associated with a higher number of traits linked to negative affect and psychoticism. When the correlation analyses were adjusted for multiple comparisons, statistically significant associations were observed between DDT scores and both detachment $(\mathrm{r}=-.318 ; \mathrm{p}=.017)$ and antagonism $(\mathrm{r}=-.294 ; \mathrm{p}=.04)$.

\section{PID and Impulsivity Tasks: Association With Severity of Dependence}

Analysis of the association between personality domains and dependence severity revealed significant positive correlations between the severity of cocaine dependence and the traits of negative affect $(\mathrm{r}=.192 ; \mathrm{p}=.037)$, antagonism $(\mathrm{r}=.224 ; \mathrm{p}=$

TABLE 1 | Correlations between personality domains and scores on impulsivity tasks.

\begin{tabular}{|c|c|c|c|c|c|}
\hline & Negative affect & Detachment & Antagonism & Disinhibition & Psychoticism \\
\hline DDT & $-.153(p=.095)$ & $-.315(p=.001)$ & $-.294(p=.001)$ & $-.216(p=.019)$ & $-.134(p=.149)$ \\
\hline IGT & $.035(p=.704)$ & $.040(p=.667)$ & $-.090(p=.335)$ & $.034(p=711)$ & $.142(p=.125)$ \\
\hline Stroop & $.232(p=.011)$ & $-.090(p=.670)$ & $.014(\mathrm{p}=.877)$ & $.125(p=176)$ & $.212(p=.021)$ \\
\hline Go/No-Go & $-.031(r=.739)$ & $-.027(r=.769)$ & $-.073(r=.431)$ & $-.029(r=.760)$ & $-.010(r=.912)$ \\
\hline
\end{tabular}


$.015)$, disinhibition $(\mathrm{r}=.216 ; \mathrm{p}=.019)$, and psychoticism $(\mathrm{r}=$ $.216 ; \mathrm{p}=.019)$. Among the impulsivity tasks, it is observed that DDT scores correlate negatively with the severity of cocaine dependence $(r=-.267 ; \mathrm{p}=.003)$, such that greater severity is associated with greater impulsivity. It was also observed that the severity of alcohol dependence is significantly correlated with the Go/no-Go false alarm rate $(r=.253 ; \mathrm{p}=.006)$. Correlation analysis adjusted for multiple comparisons revealed that the DDT scores were associated with the severity of cocaine dependence $(\mathrm{r}=-.282 ; \mathrm{p}=.031)$.

\section{PID and Impulsivity Tasks: Associations With Treatment Retention}

It was observed that time in treatment was negatively correlated with traits of negative affect $(\mathrm{r}=-.195 ; \mathrm{p}<.05)$, antagonism $(\mathrm{r}=-.232$; $\mathrm{p}<.05)$, and disinhibition $(\mathrm{r}=-.205 ; \mathrm{p}<.05)$. When applying Bonferroni's correction for multiple tests, no statistically significant associations were found between the above variables. The KRLS model, controlling for age, gender and severity of alcohol and cocaine dependence, revealed that the negative affect and IGT coefficients were statistically significant (Table 2).

Analysis of dropout/discharge from therapy with respect to the study variables revealed that those who dropped out scored higher on negative affect and psychoticism (Table 3). KRLS analysis confirmed that none of the variables analyzed show predictive capacity with respect to the type of discharge.

\section{DISCUSSION}

The objectives of this study were: i) to analyze the relationships between behavioral measures of impulsivity and personality domains; and, ii) to analyze the correlation between these variables and retention in treatment and type of discharge. As mentioned previously, very few studies have addressed the relationships between performance on neuropsychological impulsivity tasks and the big five personality traits-and even fewer have focused on the pathological domains and facets of AMPD. With regard to the second objective, Foulds et al. (56), in their review, indicate the need to study the association between personality patterns and retention in treatment, given the clinical significance of this information. Furthermore, these objectives have been addressed for the first time from the alternative model of personality disorders (AMPD) proposed in DSM-5.

The results related to our first objective partially support the hypothesis. We observed that more impulsive scores on DDT are associated with the domains of detachment (associated with introversion in the FFM) and disinhibition (low conscientiousness in the FFM), these traits and behaviors being associated with the impulse to approach drugs (33). In addition, the association with conscientiousness has also been found in studies conducted with community samples $(26,57)$. Although not hypothesized, a relationship has been found between DDT scores and antagonism domain scores. One possible explanation for this relationship could be the high comorbidity between SUD and antisocial personality

TABLE 2 | KRLS analysis for the prediction of treatment retention (days in treatment).

\begin{tabular}{|c|c|c|c|c|c|c|c|}
\hline & Avg. & SE & $\mathbf{t}$ & $P<|t|$ & P25 & P50 & P75 \\
\hline Gender (female) & -1.809 & 2.375 & -0.762 & .448 & -3.021 & -1.768 & -0.617 \\
\hline Age & 0.021 & 0.031 & 0.665 & .507 & 0.003 & 0.023 & 0.041 \\
\hline Severity of alcohol dependence & -0.023 & 0.025 & -0.933 & 0353 & -0.038 & -0.024 & -0.007 \\
\hline Severity of cocaine dependence & -0.008 & 0.020 & -0.418 & .677 & -0.016 & -0.006 & 0.002 \\
\hline Negative affect & -1.051 & 0.486 & -2.161 & .033 & -1.552 & -1.021 & -0.577 \\
\hline Detachment & -0.001 & 0.478 & -0.002 & .998 & -0.241 & -0.005 & 0.182 \\
\hline Antagonism & -0.802 & 0.441 & -1.821 & .071 & -1.103 & -0.867 & -0.491 \\
\hline Disinhibition & 0.158 & 0.419 & 0.379 & .705 & -0.040 & 0.138 & 0.433 \\
\hline Psychoticism & -0.579 & 0.495 & -1.171 & .244 & -0.878 & -0.609 & -0.223 \\
\hline DDT & -1.137 & 1.011 & -1.124 & .264 & -1.771 & -1.337 & -0.627 \\
\hline IGT & -0.027 & 0.013 & -2.119 & .036 & -0.037 & -0.029 & -0.017 \\
\hline Stroop & -0.003 & 0.005 & -0.620 & .537 & -0.005 & -0.003 & -0.000 \\
\hline Go/No-Go & -5.700 & 7.986 & -0.714 & .477 & -10.060 & -5.776 & -1.493 \\
\hline
\end{tabular}

P25: $1^{\text {st }}$ quartile 25; P50: Media; P75: $3^{\text {rd }}$ quartile.

TABLE 3 | Relationships between type of discharge, personality domains, and scores on impulsivity tasks.

\begin{tabular}{|c|c|c|c|c|c|c|}
\hline & Dropout [Mean (SD)] & Therapeutic discharge [Mean (SD)] & Mann-Whitney U & $\mathbf{z}$ & $\mathbf{p}$ & Effect size \\
\hline Negative affect & $1.89(0.56)$ & 1.64 (0.63) & 1012.5 & 2.822 & .005 & 0.26 \\
\hline Detachment & $1.12(0.59)$ & $0.96(0.67)$ & 1356.5 & 0.825 & .410 & 0.08 \\
\hline Antagonism & $0.90(0.63)$ & $0.88(0.69)$ & 1160.5 & 1.963 & .050 & 0.18 \\
\hline Disinhibition & $1.70(0.71)$ & $1.48(0.68)$ & 1309.0 & 1.101 & .271 & 0.10 \\
\hline Psychoticism & $1.17(0.60)$ & $1.01(0.60)$ & 1129.5 & 2.143 & .032 & 0.20 \\
\hline Stroop & $0.10(0.06)$ & 0.09 (0.07) & 1412.0 & 0.502 & .616 & 0.05 \\
\hline Go/No-Go & $0.06(0.03)$ & 0.07 (0.04) & 1318.0 & 0.833 & .405 & 0.08 \\
\hline DDT & $0.44(0.33)$ & $0.43(0.29)$ & 1496.0 & 0.225 & .822 & 0.02 \\
\hline IGT & 2.37 (31.87) & $3.90(20.81)$ & 1497.0 & 0.009 & .993 & 0.00 \\
\hline
\end{tabular}


disorder (ASPD) $(58,59)$, of which antagonism is a characteristic domain (51). Moreover, an association has been reported between ASPD and performance on the DDT $(60,61)$. Additional research is needed to confirm these relationships. Further, the absence of the expected correlation between disinhibition and IGT scores could be due to the fact that tasks with a poorly defined probability of success (under ambiguous conditions) are not influenced by disinhibitory personality characteristics, unlike those with explicit outcomes and probabilities (under risk conditions) (22).

The association between negative affect and Stroop performance was also anticipated from a theoretical perspective (33). This association could be due to the role played by the amygdala in mediating emotional interference in tasks that require cognitive resources, with studies showing that patients with a high degree of neuroticism (associated with negative affectivity) show excessive activation of this area (62). Nor is it surprising that scores on psychoticism are correlated with Stroop performance, since this domain includes facets related to the impairment of cognitive processes. This association has been found in other studies with people that tend to show unusual beliefs, high creativity, and disorganized personality $(63,64)$.

With respect to the second objective, it was hypothesized that traits associated with sensation-seeking would reduce treatment retention, while those associated with cooperation and persistence would improve retention (56). Thus, it might be expected that both the disinhibition domain and scores on impulsive choice tasks would play a central role in predicting retention in treatment. Consistent with previous studies, TGI scores were shown to be a predictor of treatment retention (65-67). Among the personality traits, negative affect, rather than disinhibition, emerged as a predictor of treatment retention. The fact that-contrary to our original hypothesis-negative affect appears to be a predictor of retention, could be related to the fact that scores on this personality domain involve the assessment of negative experiences and emotions (e.g., anxiety, depression, emotional lability, and hostility). Such emotions could appear in patients with addiction resulting from adaptations in the extended amygdala circuits (68). Thus, in this case, negative affectivity could be measuring the state of the patients rather than their personality traits, as some authors have pointed out when using the PID in addiction patients (50).

Although this study provides results of interest for both the investigation and clinical management of these patients, it is necessary to bear in mind a series of limitations. Possibly the most notable of these is the (low) proportion of women in our sample. Although this gender bias is an accurate reflection of the percentage of women in treatment in this study setting (69), our findings should not be generalized to women, given the differences noted by some authors in impulsivity and personality patterns. Moreover, our study was conducted with a sample of 121 patients. A larger sample size would have been desirable to improve the statistical power of the study. However, it should be noted that these types of studies are generally conducted with small sample sizessmaller than the one used here (70)—which reflects the complexity of conducting such studies. It is also necessary to take into account that the findings obtained in this work are mostly of a correlational nature, which prevents the establishment of causality between variables. Moreover, this is a transversal study, so in order to reach definitive conclusions it would be appropriate to carry out further longitudinal studies. It is also worth noting that in the literature the relationships between self-report and behavioral measures of impulsivity are usually low, which seems to indicate that they evaluate different constructs with little shared variance (71) and that attempts to find evidence for the integration of these constructs could be unsuccessful (11). Some authors claim that the confounding impact of methodological variations makes it difficult to integrate data from both types of measurement (10). Although this could be considered a limitation of the present study, it is also important to consider that both types of measures predict addiction-related behaviors (11) and that knowledge of how they are related could improve our understanding of these phenomena. As proposed by Stevens et al. (10) it would be desirable for future investigations to include assessment systems based on laboratory and self-report tests of different impulsivity constructs in order to create a true multi-trait-multimethod approach.

In spite of the limitations just mentioned, we consider that our findings contribute towards gaining a deeper understanding of the role of personality and impulsivity in addiction. Moreover, our results could contribute towards identifying patient profiles that could benefit from tailored intervention strategies that could help to improve the treatment outcomes of these patients.

\section{DATA AVAILABILITY STATEMENT}

The raw data supporting the conclusions of this article will be made available by the authors, without undue reservation.

\section{ETHICS STATEMENT}

The studies involving human participants were reviewed and approved by the ethics committee of the University of Huelva. The patients/participants provided their written informed consent to participate in this study.

\section{AUTHOR CONTRIBUTIONS}

JG-B and ÓL designed the study. EM-B wrote the first draft of the manuscript. FF-C and CD-B have been implicated in data analysis. JL-M and PP-M conducted literature searches and completed the Introduction section of the paper. All authors contributed to the article and approved the submitted version.

\section{FUNDING}

This study was supported by the "Longitudinal study about the effect of treatment on executive function recovery in patients with cocaine and alcohol dependence: implications on treatment outcomes "provided by the Delegación del Gobierno para el Plan Nacional sobre Drogas (Spain) (grant number Q7150008F-2016/034)”. 


\section{REFERENCES}

1. Spitzer RL, Kroenke Md K, Williams JBW. Diagnostic and statistical manual of mental disorders. Washington DC: American Psychiatric Association (1980).

2. Castellanos-Ryan N, Conrod P. Personality and substance misuse: evidence for a four-factor model of vulnerability. Drug abuse and addiction in medical illness. Springer: New York, NY (2012). p. 47-62.

3. Booth-Kewley S, Vickers RRJr. Associations between major domains of personality and health behavior. J Pers (1994) 62.3:281-98. doi: 10.1111/ j.1467-6494.1994.tb00298.x

4. Turiano NA, Whiteman SD, Hampson SE, Roberts BW, Mroczek DK. Personality and substance use in midlife: Conscientiousness as a moderator and the effects of trait change. J Res Pers (2012) 46.3:295-305. doi: 10.1016/j.jrp.2012.02.009

5. Kotov R, Gamez W, Schmidt F, Watson D. Linking "big” personality traits to anxiety, depressive, and substance use disorders: a meta-analysis. Psychol Bull (2010) 136.5:768. doi: 10.1037/a0020327

6. Di Nicola M, Pepe M, Modica M, Lanzotti P, Panaccione I, Moccia L., et al. Mixed States in Patients with Substance and Behavioral Addictions. Psychiatr Clinics (2020) 43.1:127-37. doi: 10.1016/j.psc.2019.10.012

7. Di Nicola M, Tedeschi D, De Risio L, Pettorruso M, Martinotti G, Ruggeri F., et al. Co-occurrence of alcohol use disorder and behavioral addictions: relevance of impulsivity and craving. Drug Alcohol Depend (2015) 148:11825. doi: 10.1016/j.drugalcdep.2014.12.028

8. Robins RW, Tracy JL, Sherman JW. What kinds of methods do personality psychologists use. In: Robins RW, Fraley RC, Krueger RF, editors. Handbook of research methods in personality psychology. New York, NY: Guilford Press (2007). p. 673-8.

9. Nigg JT. On inhibition/disinhibition in developmental psychopathology: views from cognitive and personality psychology and a working inhibition taxonomy. Psychol Bull (2000) 126.2:220. doi: 10.1037/0033-2909.126.2.220

10. Stevens AK, Blanchard BE, Littlefield AK. Impulsive dispositions and alcohol: what we know, how we know it, and where to go from here. Borderline Pers Disord Emotion Dysregulation (2018) 5.1:4. doi: 10.1186/s40479-018-0081-0

11. Sharma L, Markon KE, Clark LA. Toward a theory of distinct types of "impulsive" behaviors: A meta-analysis of self-report and behavioral measures. Psychol Bull (2014) 140.2:374. doi: 10.1037/a0034418

12. Stautz K, Cooper A. Impulsivity-related personality traits and adolescent alcohol use: A meta-analytic review. Clin Psychol Rev (2013) 33.4:574-92. doi: 10.1016/j.cpr.2013.03.003

13. Amlung M, Vedelago L, Acker J, Balodis I., MacKillop J. Steep delay discounting and addictive behavior: A meta-analysis of continuous associations. Addiction (2017) 112.1:51-62. doi: 10.1111/add.13535

14. Bechara A. Decision making, impulse control and loss of willpower to resist drugs: a neurocognitive perspective. Nat Neurosci (2005) 8.11:1458-63. doi: $10.1038 / \mathrm{nn} 1584$

15. Biernacki K, McLennan SN, Terrett G, Labuschagne I, Rendell PG. Decisionmaking ability in current and past users of opiates: A meta-analysis. Neurosci Biobehav Rev (2016) 71:342-51. doi: 10.1016/j.neubiorev.2016.09.011

16. Brevers D, Bechara A, Cleeremans A, Noël X. Iowa Gambling Task (IGT): twenty years after-gambling disorder and IGT. Front Psychol (2013) 4:665. doi: 10.3389/fpsyg.2013.00665

17. Denburg NL, Weller JA, Yamada TH, Shivapour DM, Kaup AR, LaLoggia A, et al. Poor decision making among older adults is related to elevated levels of neuroticism. Ann Behav Med (2009) 37.2:164-72. doi: 10.1007/s12160-0099094-7

18. Hooper CJ, Luciana M, Wahlstrom D, Conklin HM, Yarger RS. Personality correlates of Iowa Gambling Task performance in healthy adolescents. Pers Individ Dif (2008) 44.3:598-609. doi: 10.1016/j.paid.2007.09.021

19. Lev D, Hershkovitz E, Yechiam E. Decision making and personality in traffic offenders: A study of Israeli drivers. Accid Anal Prev (2008) 40.1:223-30. doi: 10.1016/j.aap.2007.05.009

20. Yilmaz S, Kafadar H. Investigating the relationship between decision-making processes and cognitive processes, personality traits, and affect via the structural equation model in young adults. Appl Neuropsychol: Adult (2019) 26:1-12. doi: 10.1080/23279095.2019.1576690

21. Buelow MT, Cayton C. Relationships between the big five personality characteristics and performance on behavioral decision making tasks. Pers Individ Dif (2020) 160:109931. doi: 10.1016/j.paid.2020.109931
22. Brand M, Altstötter-Gleich C. Personality and decision-making in laboratory gambling tasks-Evidence for a relationship between deciding advantageously under risk conditions and perfectionism. Pers Individ Dif (2008) 45.3:226-31. doi: 10.1016/j.paid.2008.04.003

23. Skeel RL, Neudecker J, Pilarski C, Pytlak K. The utility of personality variables and behaviorally-based measures in the prediction of risk-taking behavior. Pers Individ Dif (2007) 43.1:203-14. doi: 10.1016/j.paid.2006.11.025

24. Hirsh JB, Morisano D, Peterson JB. Delay discounting: Interactions between personality and cognitive ability. J Res Pers (2008) 42.6:1646-50. doi: 10.1016/ j.jrp.2008.07.005

25. Hirsh JB, Guindon A, Morisano D, Peterson JB. Positive mood effects on delay discounting. Emotion (2010) 10.5:717. doi: 10.1037/a0019466

26. Mahalingam V, Stillwell D, Kosinski M, Rust J, Kogan A. Who can wait for the future? A personality perspective. Soc psychol Pers Sci (2014) 5.5:573-83. doi: 10.1177/1948550613515007

27. Prabhakaran R, Kraemer DJM, Thompson-Schill SL. Approach, avoidance, and inhibition: Personality traits predict cognitive control abilities. Pers Individ Dif (2011) 51.4:439-44. doi: 10.1016/j.paid.2011.04.009

28. Dujmović M, Penezić Z. To Do or not to Do: Inhibiting Attention and Action Depending on the Level of Extraversion. Psihologijske teme (2017) 26.1:47-60. doi: $10.31820 / p t .26 .1 .3$

29. Lundgren F, Filip MH. Stroop color coding and the relationship of personality in performance: An experimental study on Stroop color coding controlling for personality traits. Småland: Linnaeus University (2019).

30. Johnson W, Bouchard TJ Jr, Segal NL, Keyes M, Samuels J. The Stroop ColorWord Test: Genetic and environmental influences; Reading, mental ability, and personality correlates. J Educ Psychol (2003) 95.1:58. doi: 10.1037/00220663.95.1.58

31. Ersche KD, Turton AJ, Chamberlain SR, Müller U, Bullmore ET, Robbins TW. Cognitive dysfunction and anxious-impulsive personality traits are endophenotypes for drug dependence. Am J Psychiatry (2012) 169.9:926-36. doi: 10.1176/appi.ajp.2012.11091421

32. Tomassini A, Struglia F, Spaziani D, Pacifico R, Stratta P, Rossi A. Decision making, impulsivity, and personality traits in alcohol-dependent subjects. Am J Addict (2012) 21.3:263-7. doi: 10.1111/j.1521-0391.2012.00225.x

33. Gullo MJ, Loxton NJ, Dawe S. Impulsivity: Four ways five factors are not basic to addiction. Addictive Behav (2014) 39(11):1547-56. doi: 10.1016/ j.addbeh.2014.01.002

34. Gullo MJ, Potenza MN. Impulsivity: mechanisms, moderators and implications for addictive behaviors. Addictive Behav (2014) 39.11:1543-6. doi: 10.1016/j.addbeh.2014.06.005

35. Waugh MH, Hopwood CJ, Krueger RF, Morey LC, Pincus AL, Wright AG. Psychological assessment with the DSM-5 Alternative Model for Personality Disorders: Tradition and innovation. Prof Psychol: Res Pract (2017) 48.2:79. doi: $10.1037 /$ pro0000071

36. Moraleda-Barreno E, Díaz-Batanero C, Pérez-Moreno PJ, Gómez-Bujedo J, Lozano OM. Relations between facets and personality domains with impulsivity: New evidence using the DSM-5 Section III framework in patients with substance use disorders. Pers Disord: Theory Res Treat (2018) 9.5:490. doi: $10.1037 /$ per0000278

37. Moraleda-Barreno E, Domínguez-Salas S, Díaz-Batanero C, Lozano ÓM, Marín JAL, Verdejo-García A. Specific aspects of cognitive impulsivity are longitudinally associated with lower treatment retention and greater relapse in therapeutic community treatment. J Subst Abuse Treat (2019) 96:33-8. doi: 10.1016/j.jsat.2018.10.004

38. Kirby KN, Petry NM, Bickel WK. Heroin addicts have higher discount rates for delayed rewards than non-drug-using controls. J Exp Psychol: Gen (1999) 128.1:78. doi: 10.1037/0096-3445.128.1.78

39. Myerson J, Green L, Warusawitharana M. Area under the curve as a measure of discounting. J Exp Anal Behav (2001) 76.2:235-43. doi: 10.1901/ jeab.2001.76-235

40. Bechara A, Damasio AR, Damasio H, Anderson SW. Insensitivity to future consequences following damage to human prefrontal cortex. Cognition (1994) 50:1-3. doi: 10.1016/0010-0277(94)90018-3

41. Hooper CJ, Luciana M, Conklin HM, Yarger RS. Adolescents' performance on the Iowa Gambling Task: implications for the development of decision making and ventromedial prefrontal cortex. Dev Psychol (2004) 40.6:1148. doi: 10.1037/0012-1649.40.6.1148 
42. Verdejo-García AJ, Perales JC, Pérez-García M. Cognitive impulsivity in cocaine and heroin polysubstance abusers. Addictive Behav (2007) 32.5:950-66. doi: 10.1016/j.addbeh.2006.06.032

43. Lang PJ, Bradley MM, Cuthbert BN. International affective picture system (IAPS): affective ratings of pictures and instruction manual. Gainesville: University of Florida (2008). Tech Rep A-8.

44. Pardo JV, Pardo PJ, Janer K. W, Raichle ME. The anterior cingulate cortex mediates processing selection in the Stroop attentional conflict paradigm. Proc Natl Acad Sci (1990) 87.1:256-9. doi: 10.1073/pnas.87.1.256

45. Spreen O, Strauss E. A compendium of neuropsychological tests: Administration, norms, and commentary. New York: Oxford University Press (1998).

46. Miele GM, Carpenter KM, Cockerham MS, Trautman KD, Blaine J, Hasin DS. Substance Dependence Severity Scale (SDSS): reliability and validity of a clinician-administered interview for DSM-IV substance use disorders. Drug Alcohol Depend (2000) 59.1:63-75. doi: 10.1016/S0376-8716(99)00111-8

47. Dacosta-Sánchez D, Fernández-Calderón F, González-Ponce B, DíazBatanero C, Lozano ÓM. Severity of substance use disorder: Utility as an outcome in clinical settings. Alcohol: Clin Exp Res (2019) 43.5:869-76. doi: 10.1111/acer.14020

48. Maples JL, Carter NT, Few LR, Crego C, Gore WL, Samuel DB, et al. Testing whether the DSM-5 personality disorder trait model can be measured with a reduced set of items: An item response theory investigation of the Personality Inventory for DSM-5. Psychol Assess (2015) 27.4:1195. doi: 10.1037/ pas0000120

49. Gutiérrez F, Aluja A, Peri JM, Calvo N, Ferrer M, Baillés E, et al. Psychometric properties of the Spanish PID-5 in a clinical and a community sample. Assessment (2017) 24.3:326-36. doi: 10.1177/1073191115606518

50. Díaz-Batanero C, Ramírez-López J, Domínguez-Salas S, Fernández-Calderón F, Lozano ÓM. Personality inventory for DSM-5-short form (PID-5-SF): Reliability, factorial structure, and relationship with functional impairment in dual diagnosis patients. Assessment (2019) 26.5:853-66. doi: 10.1177/ 1073191117739980

51. American Psychiatric Association. Diagnostic and statistical manual of mental disorders $\left(D S M-5^{\circledR}\right)$. Arlington: American Psychiatric Pub (2013).

52. Krueger RF, Markon KE. The role of the DSM-5 personality trait model in moving toward a quantitative and empirically based approach to classifying personality and psychopathology. Annu Rev Clin Psychol (2014) 10:477-501. doi: 10.1146/annurev-clinpsy-032813-153732

53. De la Rosa Cáceres A, López JR, Calderón FF, Lozano-Rojas ÓM, MoraledaBarreno E, Díaz-Batanero C. Discriminative capacity for functional impairment of the Personality Inventory for DSM-5 Short Form in patients with substance use disorder. Adicciones (2020) 0(0):1357. doi: 10.20882/adicciones.1357

54. Pons O. Statistical tests of nonparametric hypotheses: asymptotic theory. Singapore: World Scientific (2013).

55. Hainmueller J, Chad H. Kernel regularized least squares: Reducing misspecification bias with a flexible and interpretable machine learning approach. Polit Anal (2014) 22(2):143-68. doi: 10.1093/pan/mpt019

56. Foulds J, Newton-Howes G, Guy NH, Boden JM, Mulder RT. Dimensional personality traits and alcohol treatment outcome: a systematic review and meta-analysis. Addiction (2017) 112.8:1345-57. doi: 10.1111/add.13810

57. Daly M, Harmon CP, Delaney L. Psychological and biological foundations of time preference. J Eur Econ Assoc (2009) 7.2-3:659-69. doi: 10.1162/JEEA.2009.7.23.659

58. Ruiz MA, Pincus AL, Schinka JA. Externalizing pathology and the five-factor model: A meta-analysis of personality traits associated with antisocial personality disorder, substance use disorder, and their co-occurrence. J Pers Disord (2008) 22.4:365-88. doi: 10.1521/pedi.2008.22.4.365

59. Köck P, Walter M. Personality disorder and substance use disorder-An update. Ment Health Prev (2018) 12:82-9. doi: 10.1016/j.addbeh.2016.06.003
60. Albein-Urios N, Martinez-González JM, Lozano Ó, Verdejo-Garcia A Monetary delay discounting in gambling and cocaine dependence with personality comorbidities. Addictive Behav (2014) 39.11:1658-62. doi: 10.1016/j.addbeh.2014.06.001

61. Petry NM. Discounting of delayed rewards in substance abusers: relationship to antisocial personality disorder. Psychopharmacology (2002) 162.4:425-32. doi: 10.1007/s00213-002-115-1

62. Han HJ, Lee K, Kim HT, Kim H. Distinctive amygdala subregions involved in emotion-modulated Stroop interference. Soc Cogn Affect Neurosci (2014) 9.5:689-98. doi: 10.1093/scan/nst021

63. Orem DM, Bedwell JS. A preliminary investigation on the relationship between color-word Stroop task performance and delusion-proneness in nonpsychiatric adults. Psychiatry Res (2010) 175.1-2:27-32. doi: 10.1016/ j.psychres.2008.09.001

64. Carter C, Hass RW, Charfadi M, Dinzeo TJ. Probing Linear and Nonlinear Relations Among Schizotypy, Hypomania, Cognitive Inhibition, and Creativity. Creat Res J (2019) 31.1:83-92. doi: 10.1080/10400419.2019. 1580091

65. Stevens L, Verdejo-García A, Goudriaan AE, Roeyers H, Dom G, Vanderplasschen W. Impulsivity as a vulnerability factor for poor addiction treatment outcomes: a review of neurocognitive findings among individuals with substance use disorders. J Subst Abuse Treat (2014) 47.1:58-72. doi: 10.1016/j.jsat.2014.01.008

66. Stevens L, Goudriaan AE, Verdejo-Garcia A, Dom G, Roeyers H, Vanderplasschen W. Impulsive choice predicts short-term relapse in substance-dependent individuals attending an in-patient detoxification programme. Psychol Med (2015) 45.10:2083. doi: 10.1017/ S003329171500001X

67. Moraleda-Barreno E, López JR, Fernández-Calderón F, Lozano ÓM, DiazBatanero C. Personality Traits among the Various Profiles of Substance Use Disorder Patients: New Evidence Using the DSM-5 Section III Framework. Eur Addict Res (2019) 25.5:238-47. doi: 10.1159/000500806

68. Volkow ND, Koob GF, McLellan AT. Neurobiologic advances from the brain disease model of addiction. New Engl J Med (2016) 374.4:363-71. doi: 10.1056/NEJMra1511480

69. European Monitoring Centre for Drugs and Drug Addiction. European drug report 2019: Trends and developments. Luxembourg: Office for Official Publications of the European Communities (2019).

70. Domínguez-Salas S, Díaz-Batanero C, Lozano-Rojas OM, Verdejo-García A. Impact of general cognition and executive function deficits on addiction treatment outcomes: Systematic review and discussion of neurocognitive pathways. Neurosci Biobehav Rev (2016) 71:772-801. doi: 10.1016/ j.neubiorev.2016.09.030

71. Meda SA, Stevens MC, Potenza MN, Pittman B, Gueorguieva R, Andrews $\mathrm{MM}$, et al. Investigating the behavioral and self-report constructs of impulsivity domains using principal component analysis. Behav Pharmacol (2009) 20.5-6:390. doi: 10.1097/FBP.0b013e32833113a3

Conflict of Interest: The authors declare that the research was conducted in the absence of any commercial or financial relationships that could be construed as a potential conflict of interest.

Copyright (c) 2020 Gómez-Bujedo, Lozano, Pérez-Moreno, Lorca-Marín, Fernández-Calderón, Diaz-Batanero and Moraleda-Barreno. This is an open-access article distributed under the terms of the Creative Commons Attribution License (CC BY). The use, distribution or reproduction in other forums is permitted, provided the original author(s) and the copyright owner(s) are credited and that the original publication in this journal is cited, in accordance with accepted academic practice. No use, distribution or reproduction is permitted which does not comply with these terms. 